\title{
Professor Titular Tércio Sampaio Ferraz Júnior
}

\author{
A Redação \\ Aprovado com distinção em Concurso à Cadeira de \\ Introducão ao Estudo do Direito, tomou posse como Titular \\ - Professor Tércio Sampaio Ferraz Júnior, em 16-8-79, e foi \\ solenemente recebido pela Congregação em 14-11-79. \\ Apesar de extremamente jovem, o novo titular é portador \\ de um extenso e profícuo curriculum, que inclui cursos de \\ Doutoramento realizados no Brasil e no exterior, em Direito \\ e Filosofia, além de uma série de conferências e discursos, \\ realizados no Brasil, na Europa e nos Estados Unidos, sempre \\ na língua original de cada país. \\ Em seu discurso de agradecimento, o Professor Tércio \\ relembra saudosamente dois grandes mestres que muito o \\ incentivaram em sua carreira universitária, já falecidos: o \\ Professor Dino Fontana e o Professor Teófilo Cavalcanti \\ Filho. \\ Fez ainda uma retrospectiva do ensino jurídico no Brasil, \\ desde a sua instauração, em 1827, até nossos dias, ressaltando \\ os problemas que enfrenta atualmente. \\ Reafirmou sua vocação ao magistério, verdadeiro sacer- \\ dócio, e prestou seu compromisso para com o ensino jurídico, \\ a educação e o desenvolvimento da Ciência.
}

\section{O Professor Titular}

Tércio Sampaio Ferraz Júnior nasceu em São Paulo, aos 2 de julho de 1941, filho do Dr. Tércio Sampaio Ferraz e de D. Dulce Barros Sampaio Ferraz.

Fez seus estudos secundários no Colégio São Luiz, de 1952 a 1959, e bacharelou-se em Direito pela Universidade de São Paulo, tendo colado grau em 1964. Ao mesmo tempo, licenciou-se em Filosofia, também pela Universidade de São Paulo.

No período de 1965 a 1968 estudou em Mainz, Alemanha, conquistando o título de Doutor em Filosofia pela Johanes Gutenberg Universitaet zu Mainz, em 1968.

Fez o curso de Doutorado nesta Faculdade, concluindo-o em 1970.

O Professor Tércio Sampaio Ferraz Júnior iniciou suas atividades didáticas no ano de 1969, como Instrutor da disciplina "Filosofia do Direito", nesta Faculdade; como professor contratado da Faculdade de Filosofia de São Bento, da Pontifícia Universidade Católica de São Paulo, e como professor da disciplina "Filosofia da Ciência, Epistemologia e Lógica", da Escola de Sociologia e Política de São Paulo, cargos que exerceu até 1970 . 
Lecionou ainda "Filosofia da Ciência", matéria depois denominada "Filosofia e Lógica", na Fundação Armando Álvares Penteado, desde 1969.

Foi professor Assistente-Doutor, encarregado do curso de Bacharelado-noturno de 1971 a 1973, e encarregado dos seminários de Teoria Geral do Direito, em nível de pós-graduação.

Na Pontifícia Universidade Católica de São Paulo, foi Professor de Filosofia do Direito e Teoria Geral do Direito, ambas em nível de pós-graduação.

Na Pontifícia Universidade Católica do Rio Grande do Sul ministrou o curso de Sociologia do Direito, também em nível de pós-graduação.

Em nossa Faculdade exerceu o cargo de Professor Livre-Docente, na regência de três cadeiras: Filosofia do Direito (1974-1978), Introdução ao Estudo do Direito (1978), ambas no curso de Bacharelado, e, já a nível de pós-graduação, regeu o curso de Sociologia do Direito, desde 1976.

Foi ainda professor contratado da Fundação Getúlio Vargas, para a administração do curso de "Sociologia do Direito", a nível de mestrado, e "Teoria da Legislação" em nível de Bacharelado em Administração Pública, em 1977.

Obtém, em 1974, a livre-docência de Filosofia do Direito, nesta Faculdade. Em 1979, concorre à titularidade da Cadeira de Introdução ao Estudo do Direito, em concurso realizado de 12 a 14 de março de 1979. É aprovado com média 9,26 e, em 16-8-79, torna-se titular da referida cadeira, em substituição ao Professor Goffredo da Silva Telles.

Em cursos de extensão universitária, de graduação e seminários, abordou diferentes temas, ligados à sua área de especialização. Em entidades situadas no Estado de São Paulo, como AASP, Ministério Público, Rotary Club, Universidades e Faculdades isoladas, proferiu conferências e cursos sobre: Sistema Jurídico, Lógica Jurídica, Relações entre Ideologia e Direito, Legitimação do Procedimento Judiciário, além de outros assuntos ligados à Filosofia, Sociologia, Comunicações e Artes, como Relações entre Lógica e Dialética em Aristóteles, Kant e Hegel, Teoria das Categorias de Emil Lask, Técnicas de Comunicação, etc.

Em outras capitais do país, proferiu palestras, e ministrou aulas e cursos em diferentes entidades, abordando os seguintes temas: Análise sociolingüística do discurso judiciário, no curso de pós-graduação da PUC - Rio de Janeiro; sobre Sociologia 


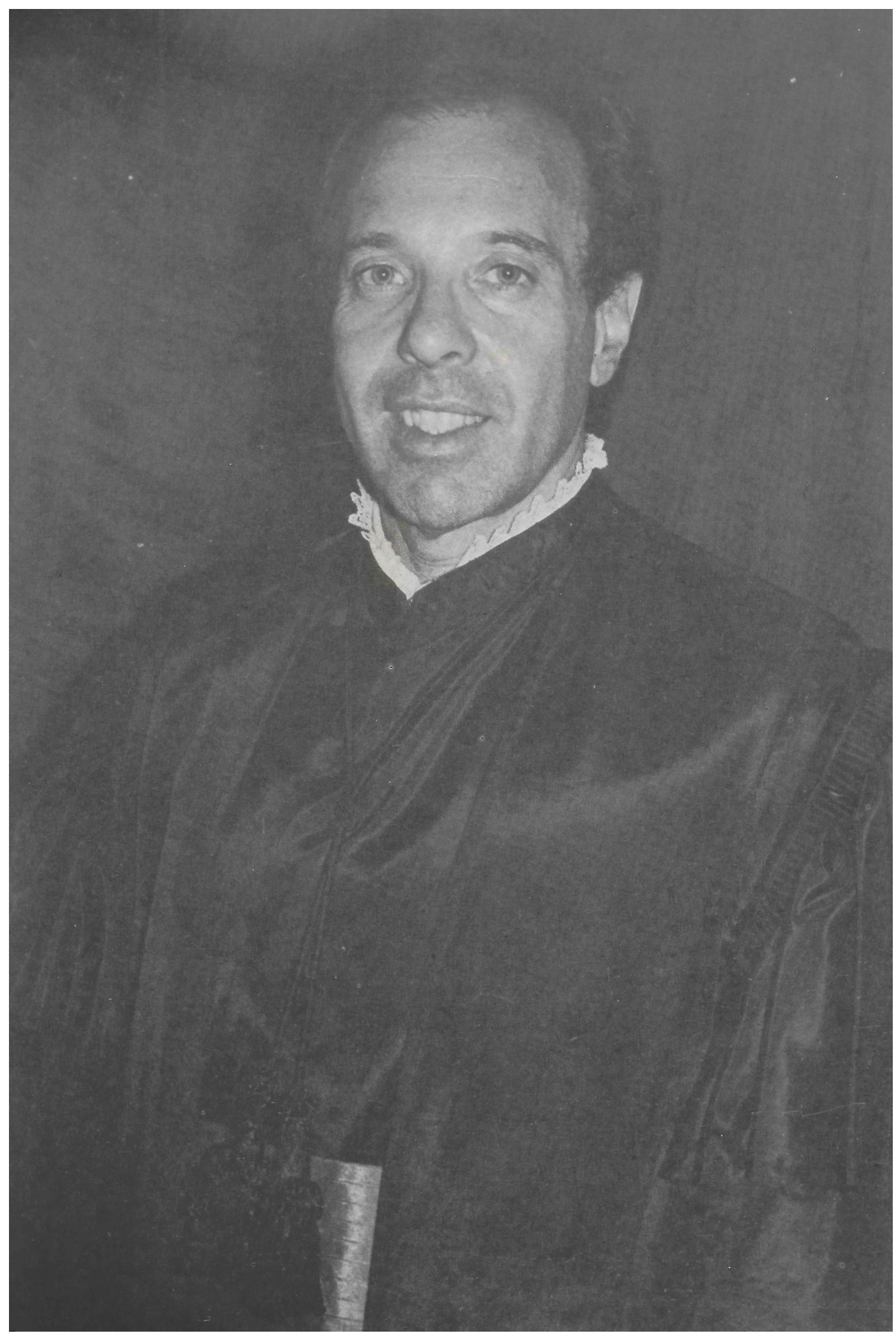


Professor Titular de Introdução ao Estudo do Direito,

Dr. Tércio Sampaio Ferraz Júnior. 
do Discurso Judiciário, na Faculdade de Direito da Universidade Federal da Paraíba; sobre Limites Constitucionais à intervenção do Estado na Economia, no $10^{\circ}$ Congresso Londrinense de Direito; sobre Filosofia do Direito no Curso de aperfeiçoamento em Ciências Jurídicas, em nível de pós-graduação, na Universidade Regional do Nordeste, etc.

Participou, ainda, de Congressos, Seminários, Painéis de Debates, Jornadas, como por exemplo, Congresso Interamericano de Filosofia, realizado em Santa Maria-RS; Congresso sobre a modernização dos cursos de pós-graduação em Direito, em Brasília em 1977, apresentando, sempre, trabalhos de grande valor doutrinário.

Participou de uma Comissão convocada pela Associação dos Advogados de São Paulo para elaborar uma proposta de Reforma Constitucional para o Brasil, do que resultou um documento enviado às autoridades.

No exterior, o Professor Tércio Sampaio Ferraz Júnior representou o Brasil em Congressos e fez uma série de conferências em Universidades. Na Alemanha, na J. Gutenberg Universitaet $\mathrm{Zu}$ Mainz, pronunciou conferência sobre "Die Wertphilosophie Miguel Reales - II Seminar; e sobre "Der systembegriff in seiner Geschichtlichen Entwicklung und der Rechtssystembegriff, no Rechtsphilosophisches Colloquium da J. Gutenberg Universitaet zu Mainz.

Foi representante do Brasil no Congresso Internacional de Direito e Filosofia Social, realizado em Gardone - Milão, em 1967; no Congresso Internacional de Filosofia do Direito e Filosofia Social, realizado na Bélgica, em Bruxelas; e no de Filosofia do Direito e Filosofia Social de Madrid, Espanha, de 1973, entre outros.

Foi coordenador do Seminário "Os Estados Unidos como modelo político, econômico, social e cultural", realizado em Harvard, em 1976, e participou ainda de um Congresso sobre o Ensino Jurídico realizado em Mar del Plata, Argentina.

Finalmente, o Professor Tércio foi membro de Bancas Examinadoras em concursos de Mestrado e Doutoramento em Direito, Doutoramento em Filosofia e Ciências Sociais e Livre-Docência em Filosofia, na Pontifícia Universidade Católica de São Paulo e do Rio de Janeiro.

O Professor Tércio Sampaio Ferraz Júnior participa ainda de atividades de criação, organização, orientação e desenvolvimento de Centros de Ensino e Pesquisa. É assessor cultural da 
Fundação de Amparo à Pesquisa do Estado de São Paulo; foi assessor do CNPq - Conselho Nacional de Desenvolvimento Científico e Tecnológico, na área de Ciências Sociais.

É membro do Instituto Brasileiro de Filosofia, do Instituto dos Advogados de São Paulo e da Associación Latinoamericana de Metodologia de la Enseñanza del Derecho, além de participar de outras entidades de ensino e pesquisa.

\section{Bibliografia}

O Professor Tércio Sampaio Ferraz Júnior apresenta rica e extensa bibliografia, abrangendo as áreas do Direito, da Filosofia, da Sociologia, da Lógica, Religião, Política e Comunicações em geral, tanto livros e monografias como artigos, publicados em revistas especializadas.

Suas obras foram escritas em diversas línguas, além do português.

\section{Livros e Monografias}

- Die Zweidimensionalitaet des Rechts als Voraussetzung fuer den Methodendualismus von Emil Lask, Anton Hain Verlag, Meisenheim Glan, 1970.

- Direito, retórica e comunicação. São Paulo, Saraiva, 1973.

- Conceito de sistema no Direito. São Paulo, Revista dos Tribunais, EDUSP, 1976.

- A ciência do Direito. São Paulo, Atlas, 1977.

- Teoria da norma jurídica. Rio de Janeiro, Forense, 1978.

- Função social da dogmática jurídica. São Paulo, Revista dos Tribunais, 1979

- Democracia e participação. Brasília, 1979.

\section{Artigos e Trabalhos Didáticos}

- Reforma agrária e reforma da Constituição. In: Carta aos Padres. São Paulo, 15(16-18), 1963.

- O proletário e a revolução. In: Carta aos Padres. São Paulo, ago. 1963.

- Aspectos econômicos da Reforma Agrária. In: Carta aos Padres. São Paulo, set.-out., 1963.

- Política de desenvolvimento. In: Carta aos Padres. São Paulo, nov. 1963.

- Análise da realidade política brasileira. In: Boletim da Universidade Católica de Campinas. Campinas, 1, 1964.

- A Igreja e as ideologias atuais. In: Boletim da Universidade Católica de Campinas, 2, 1964.

- 0 problema econômico das Paróquias. In: Carta aos Padres. São Paulo, maio-jun., 1964. 
- O significado da pintura moderna. In: Boletim do Rotary Club de S. Paulo-Norte. São Paulo, 01.XIII, 1964.

- La noción Aristotélica de Justicia. In: Atlantida. Madrid, 8(38), mar.-abr., 1969.

- Justicia y Tópica Jurídica. In: Estudios de Derecho, 29(77), mar. 1970.

- Algumas observações em torno da cientificidade do Direito segundo Miguel Reale. In: Revista Brasileira de Filosofia. São Paulo, 19(74), 1969.

- O papel da Dialética em Aristóteles, Kant e Hegel. In: Revista Brasileira de Filosofia. São Paulo, 20(80), 1970.

- Einige Bemerkungen zu Miguel Reales Begriff der Wissenschaftlichkeit des Rechts. In: Archiv fuer Rechts-und Sozialphilosophie. v. 1 - LVI/2 Wiesbaden, 1970.

- Da possibilidade de o governo das coletividades ser confiado a cientista. In: Anais do Simpósio sobre Ciência e Humanismo. São Paulo, 1971.

- Curva e Demanda, Tautologia e Lógica da Ciência. In: Ciências Econômicas e Sociais. Osasco, 6(1), 1971.

- Direitos do Homem, Positivação do Direito e Perversão ideológica. In: Anales de la Cátedra Francisco Suarez. Granada, 12(2), 1972.

- 0 direito ao delito? Observaçōes em torno da "Teoria Pura do Direito" de Hans Kelsen. In: Por que? Supl. do Centro de Pesquisas Experimentais, 2. Distribuído por Tribuna da Imprensa - Rio de Janeiro, 13-6-73.

- Direitos do Homem. In: Por que? Supl. do Centro de Pesquisas Experimentais, 1. Distribuído por Tribuna da Imprensa. Rio de Janeiro, maio, 1973.

- O papel da dialética em Aristóteles, Kant e Hegel. In: Revista de Estudos Universitários. São Paulo, s(3), 1971.

- Pragmatische Funktionen des juristischen Redens. In: Anuario de Filosofia del Derecho. Madrid, 1973.

- Dimensão axiológica do direito. In: Presença Filosófica. Rio de Janeiro, s(3), out.-dez., 1977.

- Pesquisa jurídica: avaliação e perspectivas. Publicação do CNPq. Brasília, 1977.

- A filosofia como discurso aporético. In: Revista Latinoamericana de Filosofia. Buenos Aires, 1(1), mar., 1975.

- Concepção de Sistema Jurídico no pensamento de Emil Lask. In: Revista Brasileira de Filosofia. São Paulo, 26(103), 1976.

- A noção de norma jurídica na obra de Miguel Reale. In: Ciência e Cultura. São Paulo, $26(11), 1974$.

- A presença do pensamento alemão na Filosofia do Direito no Brasil. Ed. bilingüe port./alem. In: Beitrag zu den Brasilianisch deutschen Beziehungen. Bad-Godesberg, 1978.

- Perversão ideológica nos Direitos Humanos. In: Ciência Penal. São Paulo, s, 1974 .

- Alguns aspectos pragmáticos da tomada de decisão com especial referência ao Mercado Bursátil. (em colab.) In: Revista Brasileira de Mercado de Capitais. Rio de Janeiro, 1, set.-dez., 1974.

Há ainda uma série de artigos do Professor Tércio que serão publicados em revistas especializadas:

- Rhetorisch-pragmatische Analyse der Erlaubnisnorm. a sair in: Festchrift fuer Theodor Viehweg. 
- 11 de agosto de 1827 - Fundação dos Cursos Jurídicos no Brasil, a sair na Revista Estudios de Derecho. Meddellin - Colombia.

- O Estado Interventor e a Ordem Econômica na Emenda Constitucional de 1969. A sair no volume em homenagem ao Prof. Cesarino Júnior.

- Pressupostos Filosóficos da Interpretação, a sair em livro em homenagem ao Prof. Recaséns Siches.

O Professor Tércio publicou ainda uma série de artigos sobre Direito, Política e correlatos, em jornais de grande circulaçẩo na Capital.

No Jornal da Tarde, da Empresa "O Estado de São Paulo", publicou :

- O Dilema Americano - em 11-3-73.

- Governo e Consenso - 17 e 18-2-76.

- Vale a pena votar? - 9 e 10-3-76.

- Executivo e Tecnocracia - 1-4-76.

- A Morte da Democracia - 29-4-76.

- A Massificação do Ensino - 13-7-76.

- O Ensino Jurídico - 15-9-76.

- A Intervenção na Economia - 5-10-76.

- A Crise da Sociedade Disciplinar - 3-11-76.

- A Centralização do Poder - 22-12-76.

- Apenas um dos Momentos da Crise - 9-2-77.

- Essas Leis são Sérias? $\longrightarrow$ 25-1-77.

- Para que serve um Congresso? - 26-4-77.

- A Democracia Relativa - 3-6-77.

- A Burocultura - 17-6-77.

- Ciência e Política - 8-7-77.

- Memórias do Direito no Brasil - 11-8-77.

- Comércio e Relações Internacionais (Resenha) de Celso Lafer - 27-8-77.

- O Imperativo da Legalidade - 31-8-77.

- Direito e Violência - 15-9-77.

- A Violência Legal é Legítima? - 6-10-77.

- Em busca da Dignidade Perdida - 15-10-77.

- Democracia: Realidade ou Utopia? - 29-10-77.

- Os Dilemas do Estado Interventor - 24-11-77.

- Terrorismo e Estado de Direito - 25-11-77.

- O AI-5 e a Crise Constitucional - 6-12-77.

- Uma Política de Avanços e Recuos - 18-1-78.

- Rumo à Democratização - 9-2-78.

- Poder Central - 20-2-78.

- Os Direitos Humanos são também Relativos? - 28-3-78.

- A Democracia de Geisel -- 6-4-78.

No Jornal do Brasil, publicou:

- A Dimensão Social da Democracia - 30-10-77.

- Pelé e o Significado do Voto - 1977. 
- As Fábricas de Acadêmicos - 17-12-77.

- A Palavra da Igreja, Política e Ideologia - 20-1-78.

- Judiciário e Cassações - 27-3-78.

Em O Estado de São Paulo, publicou:

- Liberdade de Imprensa e Escândalo - 16-12-77.

Além desses artigos publicados, o Professor Tércio é autor de resenhas, que foram publicadas em periódicos especializados, e de verbetes sobre vários assuntos, publicados em enciclopédias.

\section{A Recepção ao Novo Titular}

Aos 14 de novembro de 1979, reuniu-se a Congregação dos Professores da Faculdade de Direito, no salão nobre, para a cerimônia de recepção ao novo Titular, Professor Tércio Sampaio Ferraz Júnior.

A sessão, presidida pelo Diretor, Professor Antônio Chaves, contou com a presença de personalidades do mundo jurídico, professores, alunos, amigos e familiares do homenageado.

O Professor Miguel Reale, num brilhante discurso, salientou as qualidades do novo Titular, como cientista, cultor da Ciência Jurídica, Filósofo e Professor, além de mencionar a importante contribuição bibliográfica do Prof. Tércio.

O novo Titular agradeceu a homenagem que the foi prestada, ao Professor Miguel Reale, por cujas mãos entrou na Faculdade, ao Professor Goffredo, paraninfo de sua turma, e reafirmou sua vocação ao magistério, verdadeiro sacerdócio, prestando seu compromisso para com o ensino jurídico, a educação e o desenvolvimento da Ciência.

\section{Saudação do Professor Miguel Reale *}

Quando percorro a Congregação desta Faculdade verifico que apenas dois dos presentes não foram meus alunos. Isto me traz um sentimento misto de vaidade e saudade. De vaidade por ter podido contribuir à informação e formação de jovens que escolheram esta Casa para se dedicar às tarefas sempre árduas e renovadas da Ciência Jurídica. De saudade antecipada de quem está vos falando talvez pela última vez, porquanto o ano próximo, deverei deixar por força de lei as funções de professor. Sentimento especial porque me cabe a

*. O discurso de saudação do Professor Miguel Reale foi tomado por gravação e revisto pelo autor. 
alegria de saudar o jovem professor e caríssimo amigo Tércio Sampaio Ferraz Filho, cuja vocação para os estudos filosóficos me foi dado conhecer desde o início das primeiras aulas de Filosofia do Direito. Ainda não havia Departamento, ainda não era hábito realizar seminários, mas isso não impedia ao professor, efetivamente dedicado à sua disciplina, de compreender desde logo quais eram aqueles que revelavam aptidão e capacidade para trazer à Ciência do Direito mais do que simples presença, uma contribuição criadora de protagonista.

Desde o início percebi que o colega, que hoje recebemos com tanto carinho, tinha qualidades excepcionais para o exercício do magistério. O magistério é uma das tarefas mais difíceis e complexas das que podem ser confiadas ao homem, porquanto não bastam o preparo, a erudição, ou o conhecimento por mais pormenorizado que seja de um campo do saber, mas exige compreensão de seu sentido cultural e ético e sobretudo sentimento de responsabilidade perante as gerações futuras. Costumo dizer que nós, professores, gozamos de um privilégio que é o de nos prolongarmos no tempo através de nossos alunos, e daqueles com os quais tivemos um diálogo espiritual; a nossa personalidade permanece, perdura com uma forma especial de temporalidade.

Ensinar, na realidade, não é função voltada para o passado, nem tampouco visão retrospectiva do que se viveu, mas é, antes de tudo, vivência do presente em sentido prospectivo de futuro. Esta a missão do professor, a sua dignidade específica, algo que lhe assegura uma categoria própria no plano das atividades espirituais.

Meu caro Tércio, a sua presença muito jovem como titular nesta Faculdade não surpreende a quem pôde acompanhar desde o início a sua atividade. Lembro-me, como se fosse hoje, de sua visita à minha casa em companhia de seu nobre progenitor. Foi um momento em que senti profunda emoção, ao perceber com que sentimento de responsabilidade o jovem professor, já em formação, ia deixar o Brasil para completar sua cultura na Alemanha.

Destacando-se por alguns anos do que lhe era mais caro, Tércio deu exemplo de dedicação, à qual se referiram com entusiasmo professores como Von Rintelen e Theodoro Viehweg. Teve o sentimento de que lhe cabia demonstrar que o brasileiro não é esse improvisador displicente a que se referem alguns quando tratam dos problemas da América Latina, mas, ao contrário, um homem como qualquer outro do mundo da 
cultura mais elevada, capaz de se dedicar com afinco e seriedade às funções da pesquisa e à revelação de novos conhecimentos.

A feitura de sua tese, elegendo um tema original como era o de Emil Lask na temática cultural alemã, sobretudo no âmbito da Filosofia Jurídica, já demonstrava uma de suas qualidades que é aceitar o desafio de assuntos ainda não versados, de investigações que exigem poder de iniciativa e também perseverança na busca das origens e pressupostos das doutrinas. A sua tese, defendida com brilhantismo e distinção na Alemanha, converteu-se em seu trabalho de doutoramento que esta Casa conserva com orgulho, como uma contribuição ao mesmo tempo de natureza histórica e dogmática. Aliás, em toda a sua obra a compreensão lógico-normativa do Direito jamais andou separada da visão histórica e da compreensão social dos conteúdos das regras jurídicas. A perspectiva histórica de Lask, que foi sem dúvida o grande iniciador de uma das perspectivas mais fecundas da Filosofia do Direito contemporâneo, fixou, de maneira clara, o rumo que ia ser seguido ao longo de sua vida de estudioso. A convivência intelectual com mestres alemães, prolongando aquela que já levava do Brasil, foi aos poucos modelando o seu novo sistema da compreensão da Ciência Jurídica.

o Direito, meus amigos, neste século tão atormentado, tem passado por transformações profundas, exigindo novas fórmulas compreensivas. Não é apenas o cuidado deste ou daquele problema isolado que, hoje em dia, se insere na preocupação do jurista. $\mathbf{E}$ antes a compreensão totalizadora da experiência jurídica e, ao mesmo tempo, a busca de novas formas de captação dessa realidade e de novos processos de interpretação das prescrições normativas, em função de seus destinatários, sejam eles órgãos do Estado ou pessoas comuns que compõem a sociedade civil.

Ora, os seus livros seguem essa nova orientação, com consciência dos valores que já nos são próprios. No Brasil, infelizmente, o diálogo cultural, inclusive no campo do Direito, tem sido, por assim dizer, triangular. Não brota da íntima vivência da linha de pesquisa brasileira, mas tem sido, ao contrário, o reflexo do pensamento estrangeiro em nosso País, através de sucessivas gerações, de tal maneira que uma geração dialoga com a anterior servindo-lhes de mediação alguns escritores estrangeiros, cujas obras nem sempre superam as aqui elaboradas. 
Se há um programa que merece nosso apoio é o de superar essa forma de alienação cultural que ainda nos domina, não raro devido ao fátuo desejo de ostentar erudição, pois, uma cultura somente adquire plena maturidade quando se desenvolve no íntimo de sua própria experiência, na imanência de seus próprios valores. Isto não significa, de maneira alguma, desvinculação com as grandes fontes inspiradoras européias ou norte-americanas, mas sim a consciência de que nós devemos receber o pensamento estrangeiro como quem acolhe em sua casa uma visita que vem enriquecer a nossa convivência, sem nos privar de nossa intimidade. $O$ sentimento próprio da cultura jurídica brasileira está cada vez mais se afirmando, e esse é um dos pontos que desejo pôr em realce em seus escritos, que não se limitam a invocar autores alienígenas, como se fossem autênticas ou merecedoras de fé somente as "verdades importadas". O primeiro dever de um jurista é conhecer, antes de mais nada, o que já foi pensado e escrito no Brasil, sabendo manter um diálogo "interna corporis", seja acolhendo idéias, seja as submetendo ao crivo de uma crítica serena e construtiva. É tão-somente assim que lograremos assumir posição autônoma e relevante no diálogo universal das idéias.

É claro que, quando nada possuímos em dado campo da ciência, será inútil fabricar valores postiços, mas esse artificialismo é tão condenável como o ato pretensioso de voltar as costas às contribuições dos escritores nacionais. São dois males que, a bem ver, maculam as culturas subdesenvolvidas.

Mas voltemos ao sentido da obra do colega que hoje recebemos, para salientar como um valor positivo, que em nenhum de seus livros encontro um entusiasta do formalismo jurídico. Alegra-me, com efeito, verificar que Você não se satisfaz com os aspectos exteriores da "regula juris", perdendo de vista a problemática existencial, social e histórica. É isto o que observo quando se dedica à análise do "sistema do Direito", o qual não é visto como um simples escalonamento de proposições normativas, à maneira de Kelsen, mas sim como um complexo arquitetônico de modelos que se entrelaçam, se conflitam e se contradizem, e num processo que reflete acertos e contradições da vida humana. O desejo de ver na norma jurídica o que nela há de pergunta e não apenas de resposta é bem o caminho exigido do jurista pertencente a uma sociedade em acelerada mudança. E o que observo, outrossim, naquela que considero, talvez, a sua obra mais sistemática e internamente mais bem travada, a "Teoria da norma jurídica". Mais uma vez a regra 
de Direito não é vista apenas como enunciado lógico, mas apreciada sob ângulo bem pouco cultivado na Ciência Jurídica universal que é o da pragmática jurídica.

A sua contribuição, meu caro amigo Tércio, à pragmática jurídica revela aspectos de grande originalidade confirmando a sua capacidade analítica, ao mesmo tempo amorosa de concreção. Não há razão alguma para se estabelecer alternativa entre lógica, de um lado, e experiência, do outro. Jamais me conformei com a desolada afirmação de Wendell Holmes de que a vida do Direito não tem sido Lógica mas sim Experiência. Penso que o dever do jurista, sobretudo nas épocas de crise de estrutura, não é aceitar essa alternativa entre Lógica e Experiência, mas, ao contrário, correlacioná-las numa unidade viva que nos dê o sentido real da norma jurídica. Parece-me ser essa a diretriz de suas pesquisas e de seu compromisso cultural.

Quando terminei a leitura de seu trabalho Teoria $d a$ Norma Jurídica, não digo que tenha concordado com todas as suas conclusões, pois, em meu espírito vi nascer uma série de perguntas e de dúvidas. Isto não deve causar surpresa, porquanto até mesmo as ciências exatas, tal como a Epistemologia contemporânea o demonstra, somente são ciências por serem refutáveis, por exigirem a todo instante a sua própria revisão, a fim de atingir-se o valor de verdade, que será tanto mais nosso quanto mais o espalharmos pelo mundo, e será tanto mais nosso quanto mais exigir de nós novas pesquisas e novas investigações.

A inexauribilidade do valor da verdade é como a inexauribilidade do valor da justiça. Por mais sentenças justas que houver, jamais deixará de haver possibilidade de novas e mais adequadas sentenças justas. Por mais que possamos responder a novas perguntas restará sempre uma dúvida, restará sempre uma aporia, restará sempre uma nova alternativa a estimular nosso pensamento. É essa compreensão viva e existencial do Direito que faz com que Tércio Sampaio Ferraz Júnior dê tamanha importância ao problema da comunicação, da Tópica, da Retórica. Não se trata evidentemente da Retórica passada, oca e vazia, que se perdia apenas nos sentidos expressionais exteriores e convencionais, mas de uma nova técnica de persuasão, da Lógica do razoável que é inseparável do Direito, cuja problemática implica uma harmonia essencial, e sempre difícil, entre os fins almejados e a "decisão do poder"

Eis outro aspecto que me agrada em sua contínua pesquisa: não ter receio do poder. Ai do jurista que fecha os 
olhos para o poder, porquanto está, sem o perceber, abrindo caminho para o arbítrio. $O$ poder deve ser afrontado pelo jurista para ser colocado onde e como ele deve ser situado, ou seja, como poder de decisão encapsulado num complexo de pressupostos axiológicos e fáticos. O seu conceito de "decibilidade", que está a merecer de sua parte mais completos desenvolvimentos, é central para a compreensão da norma jurídica, sobretudo para que nós juristas assumamos cada vez mais a responsabilidade que temos de tornar racional e lógico mesmo aquilo que muitas vezes é fruto de pressões e de interesses irracionais. A tragédia, usemos esta palavra sem receio, a tragédia é que a responsabilidade do jurista nasce do dever de interpretar e aplicar uma regra de cuja elaboração bem poucas vezes é partícipe. Nasce, pois, do fato de que nos cabe interpretar uma regra que muitas vezes não é expressão de uma elaboração racional e lógica na tranqüilidade do saber científico, mas, ao contrário, representa o resultado de pressões obscuras de interesses nem sempre compatíveis com a dignidade dos atos humanos.

Não cabe a nós, juristas, elaborar as normas, mas cabe a nós interpretá-las; e como, no fundo, a regra de direito é a sua interpretação, a nossa responsabilidade se converte, tudo somado, e se apura no ato hermenêutico. A hermenêutica, cuidadosamente entendida, dinamiza a Ciência do Direito, apara-lhe as arestas, quebra resistências, insere o preceito particular no contexto geral do ordenamento, supre lacunas, integra, em suma, as prescrições legais particulares no conjunto do ordenamento jurídico, que não se reduz a um sistema formal de regras, mas é antes uma realidade viva e dinâmica, para cujo entendimento concreto é indispensável não converter a norma jurídica em meras formas lógicas. Nada é mais necessário, hoje em dia, ante a sereia da Axiomática jurídica, que nos tenta com os seus valores falazes de certeza isenta, do que a compreensão concreta, experiencial das regras de direito!

É graças a essa visão concreta que conseguiremos operar o direito como instrumento do bem comum, o qual, como já dizia em minha tese de concurso em 1940, não é senão a justiça objetivamente entendida. Bem comum que, como diz Luigi Bagolini, deve também ser compreendido como intersubjetividade, diálogo cada vez mais eqüitativo e intercambiável no seio da comunidade. É na linha desse pensamento que, penso eu, situa sua obra, e espero que ela se enriqueça, cada vez mais, de sentido existencial. 


\section{Discurso de agradecimento do Professor Tércio Sampaio Ferraz Júnior.}

Vivo, neste instante, um momento importante da minha vida. Passados os anos da escolaridade, os felizes caminhos da universidade, os anos probatórios do doutoramento, da docência-livre, eis-me agora chegando a um ponto decisivo da carreira. E a posse solene, o ato festivo de recepção do novo professor significa, sem dúvida, a manifestação de apreço dos colegas, dos alunos. É um ato alegre e feliz.

Não posso negar, contudo, que em meio à efusividade material deste momento, minha mente divaga, assaltada pela notícia inesperada da morte de um antigo mestre, ainda dos bancos escolares, meu professor de português e latim no velho Colégio São Luís, e que foi um dos primeiros a estimularem o meu pensamento, a minha imaginação e a minha vontade para a realização de uma carreira acadêmica. A morte do professor Dino Fontana faz-me lembrar esta outra figura exemplar de dedicação ao trabalho, às excelências da vida simples e meritória do mestre humilde que foi Theófilo Cavalcanti Filho, cuja morte rompeu bruscamente uma carreira que deveria estar culminando neste momento, nesta Faculdade, nesta disciplina.

Perdoem-me todos, se é a morte a idéia que ronda o meu sentimento neste instante. Mas ela não vem de todo despropositada. Afinal já Platão assinalava que a filosofia é uma meditação sobre a morte e a reflexão sobre a vida e seus sucessos, escreveu Cícero, é uma commentatio mortis. E a morte de que se trata é a de dois mestres queridos, a morte de alguém cuja vida foi dedicada ao magistério, esta profissão que muitos identificam a um sacerdócio, mais pungente e angustiante, contudo, que a própria vida sacerdotal, porque um sacerdócio de transcendência imediata, que termina e se renova a cada geração que passa.

A morte destes dois mestres e amigos faz-me pensar, afinal, no compromisso que assumo neste instante: o compromisso do ensino, da educação e do desenvolvimento da ciência. Um compromisso que é uma espécie de juramento de fidelidade a certos princípios e objetivos, mas que é também a exigência de uma tomada da realidade que vivemos.

Desde o instante em que as civilizações primitivas foram encontrando a sua forma própria, ethos vivencial, surgiu a educação como maneira pela qual os povos procuram perpetrar seu modo de ser material e espiritual. A educação, como disse 
Jaeger na sua Paideia, enquanto função da comunidade humana é algo tão generalizado e necessário, é processo que permeia tão profundamente toda a realidade social, que é natural que simultaneamente a reflita e sobre ela aja. Como agente e reflexo, a educação nas suas relações com o sistema social não só desperta debates sobre o seu papel específico, como espelha os problemas com os quais a sociedade se defronta perenemente. E uma das expressões mais recentes e angustiantes destes problemas é o libelo de certas correntes niilistas, anarquistas e utópicas, como o de Ivan D. Illich, que clama por uma desescolarização da sociedade, que luta pela eliminação de todas as instituições sociais, sobretudo, as estruturas centralizadas e burocráticas, conformando-se, no máximo, com instituições espontâneas de tipo descentralizado e associativo. O ataque radical ao Estado, à escola, à universidade, ao hospital, ao hospício que ali se encontra apresenta sugestões alternativas com baixo índice de realismo e coerência. Mas serve, ao menos, o necessário de reavaliação agônica do sistema educacional.

Como professor universitário de uma Faculdade de Direito de honrada e expressiva tradição como é o Largo de São Francisco, há dois temas que exigem a minha atenção e a minha palavra, sobretudo, neste momento da vida brasileira. Um deles se refere à educação como meio de aperfeiçoamento humano em termos de participação do homem nos resultados do desenvolvimento para o qual ele contribui. $O$ outro se reporta à educação como instrumento deste desenvolvimento.

No caso da educação jurídica entre nós é preciso reconhecer, friamente e sem retóricas ilusões, que, inicialmente, no período que vai da sua instauração em 1827 até o fim da 1. ${ }^{\mathrm{a}}$ República, as funções sociais construtivas ao estudo do direito eram generalizantes e pouco profissionalizantes. A criação dos cursos jurídicos ocorria numa conjuntura marcada pelo individualismo na organização política do Estado, pelo liberalismo nas relações econômicas e pelo romantismo da literatura. $O$ país era ainda dominado por um sistema tradicional de autoridade, ligado à estrutura familiar, como o pai, o padre ou o chefe político local. Neste contexto, os cursos jurídicos viriam a representar a lenta penetração de padrões técnicos, a tentativa de substituição dos padrões tradicionais de autoridade, de vida econômica e social, por um sistema legal, nacional e impessoal, que pretendia repousar sobre princípios gerais e ser aplicado segundo critérios objetivos. Os juristas que se formavam, contudo, não foram, desde o início, estritos 
profissionais do direito. Muito mais do que isto, os bacharéis eram elementos nas instituições políticas do país, como legisladores, administradores, diplomatas, literatos. Por isso, durante mais de um século, as Faculdades foram mais um ambiente material de curiosidade e debate intelectuais. Nelas, a formação curricular tinha uma importância relativa na formação cultural em que se lia, se doutrinava e se discutia História, filosofia, economia, traçando-se as linhas básicas do estilo nacional, desta figura por vezes chamada pejorativamente de bacharel. O certo, porém, é que a formação do jurista era feita para além da própria instituição curricular.

$\mathrm{Na}$ verdade, mesmo para aquela elite a educação era apenas um veículo de adestramento em técnicas letradas, de transmissão de hábitos intelectuais simbólicos de condição de homem civilizado. De resto, permanecia a concepção dominante de que era antes pelo convívio e pela própria experiência cotidiana que se adquiria o traquejo para desempenhar os papéis sociais existentes.

É certo que, no correr dos anos, esta situação se alterou, principalmente em virtude dos surtos de crescimento urbano, das tendências para a industrialização, das mudanças na participação popular no processo político, do crescimento vegetativo, da formação de novos padrões de vida. Apesar disso, as transformações não foram tão profundas nem homogêneas, de modo a provocar uma revolução na forma como a educação jurídica é avaliada. Não se nega que houve modificações, pela importação de técnicas, conhecimentos e valores. Apesar disso, o processo de assimilação destas importações encontrou uma herança que dificulta a sua atualização plena, donde a sua força relativamente baixa, sobretudo nos dias de hoje, para desencadear inovações essenciais.

Quem observa, embora limitada e superficialmente, a realidade brasileira pode notar que a educação universitária permanece um privilégio econômico e social. De um lado, porque só uma minoria pode arcar com os ônus diretos e indiretos da educação dos imaturos. De outro, porque a compreensão da importância da instrução e sua valorização social dependem de convicções compartilhados, em geral, por pequenos círculos sociais dominantes. Ou seja, a desigualdade econômica, social e cultural, afetada por diferenças regionais, tende a fomentar condições impróprias ao aproveitamento das oportunidades educacionais. Além disso o impacto negativo de uma sociedade subdesenvolvida estabelece uma contradição 
entre as necessidades prementes de renovação e os usos educacionais vigentes. Em conseqüência, o ensino do direito, diante de uma sociedade que sofistica e racionaliza suas técnicas, valores e princípios, atesta a presença de mecanismos educacionais seletivos, rígidos e generalizantes, que lhe dá uma feição elitista e aristocratizante.

O iluminismo educacional acreditou, durante muito tempo, que a escola e a universidade constituíam um fator, até mesmo decisivo, do progresso e do desenvolvimento humano. A história tem comprovado, porém, o caráter ilusório deste esquema simplista. Nem sempre a pura expansão das oportunidades educacionais altera a diferença entre os homens em termos de participação no desenvolvimento social, fruto do seu trabalho. Assim, às vezes, quando a educação realiza a função de integrar o jovem no mercado profissional, ela pode estar apenas viabilizando os padrões de igualdade e desigualdade prevalecentes na sociedade.

No caso brasileiro, o estilo de desenvolvimento praticado no período de após-guerra, foi caracterizado por uma ênfase na produção de bens de consumo, basicamente destinados à classes mais altas dos grandes centros urbanos, privilegiando-se tecnologias intensivas no uso de capital, gerando uma estrutura de trabalho bastante desigual. Cresceu desigualmente a demanda profissional, ocorrendo desníveis acentuados de remuneração, acentuando-se desde então a concepção de renda. Mas o processo de industrialização repercutiu muito mais em termos de expansão quantitativa do ensino do que qualitativa.

É sabido, neste sentido, que o ensino jurídico conheceu, sobretudo na década de 70, uma enorme e desequilibrada expansão. Mas este crescimento acabou por acentuar a pequena abertura e estreita diferenciação na estrutura de empregos. Começamos a formar cada vez mais juristas, sem que isto provocasse, porém, uma alteração no mercado de trabalho, pois continuamos a formar um tipo de jurista com estreitas possibilidades de atuação numa sociedade que se transforma. $\mathrm{E}$ o efeito final, em termos de política educacional, é, então, óbvio: embora estejamos, aparentemente, mobilizando maior soma de recursos e fatores, na realidade consumimos riquezas para expandir um tipo de ensino jurídico que não proporciona o rendimento necessário e desejável.

o valor do ensino para um povo é determinado historicamente, pelas vinculações da experiência educacional com os 
interesses e ideais sociais, particulares ou comuns, das classes existentes. Sabemos que, no Brasil, até a implantação da República e os surtos sociais, políticos e econômicos do segundo quartel deste século, o uso social que se deu à instrução manteve-a presa a interesses e concepções que a converteram plenamente em um símbolo de status. Ser ou não ser instruído equivalia a ser ou não ser ignorante, atrasado, dependente. Isto fez com que todo o ensino tomasse um sentido divorciado das necessidades sociais preenchidas fora da instituição escolar, dando a esta última um caráter diletante, como se a educação fosse um mero componente do perfil do homem civilizado.

Pois bem, este contexto social marcou profundamente $o$ ensino jurídico entre nós. Ele explica, talvez, de um lado, o alheiamento do próprio estudante dos problemas da educação e, de outro, a descontinuidade e a relativa ineficácia das reformas do ensino jurídico.

Quanto ao primeiro ponto é preciso reconhecer que, na maioria das Faculdades de Direito, o estudante permanece incapaz de se dar conta da situação imprópria, inadequada e indesejável do ensino que se lhes oferece, prevalecendo um certo silêncio e mesmo indiferença que significa antes uma acomodação à concepção diletante e aristocratizante da sua formação, onde o diploma conta mais que o benefício social do aprendizado. Prevalece a idéia de que o tirocínio necessário para a execução das tarefas sociais é obtido muito mais no comércio social da vida cotidiana. $\mathrm{Na}$ verdade, pesquisas têm revelado que tanto professores quanto alunos de direito, de graduação e de pós-graduação têm o ensino como atividade secundária, donde se observou que qualquer modificação na estrutura tradicional dos cursos jurídicos implicaria um impacto que encontraria na apatia da maioria um enorme e relevante obstáculo. Embora haja importantes exceções, e as recentes mobilizações em termo de problemas da formação jurídica nesta casa, por parte de alunos e mestres, são uma saudável manifestação de inconformismo, a verdade é que as pressões para mudar são, em geral, pequenas, pressionando-se, ao contrário, para a perpetuação de um ensino desvinculado da realidade, genérico, ilustrativo e diletante.

Quanto ao segundo ponto referente à ineficácia das reformas, é preciso dizer que o lado mais dramático, talvez, da realidade educacional jurídica entre nós está, provavelmente, na conversão do professor numa simples peça da empresa educacional, dele não se esperando, senão, uma produção estereotipada, obtidas por vias rotineiras. Com isto, o professor, 
para quem o magistério é subemprego, ou não tem uma visão adequada do lado construtivo de seu papel intelectual ou se a tem, não dispõe de recursos para pô-la em prática e desiste com o tempo. Com isto, uma das fontes mais eficientes para despertar a consciência crítica das Faculdades é silenciada e mentalizada no seu nascedouro. Por sua vez, os teóricos da educação, os reformadores educacionais, os que têm acesso aos centros de poder que definem a política do ensino, acabam falando para si mesmos, elaborando planos nacionais que valorizam excessivamente grandes objetivos, e que não encontram eco nem aproveitamento na realidade do dia-a-dia.

De um modo geral, desde o século XIX, a expansão da técnica e a ampliação da divisão do trabalho, com o desenvolvimento do capitalismo, levaram à necessidade da universalização do saber ler, escrever e contar. A educação, pouco a pouco, deixou de constituir uma ocupação ociosa, para ser uma fábrica de homens utilizáveis e adaptáveis. Isto nos conduziu a concepções desenvolvimentistas da educação, cuja preocupação maior consiste em formar indivíduos cada vez mais adaptados ao seu trabalho, capacitados, porém, a modificar o seu comportamento em função das mutações sociais. Não interessa o homem embrutecido pelo trabalho sufocante do desenvolvimento acelerado, mas um ser consciente de sua responsabilidade na vida social. Mas é isto que o ensino jurídico vigente não está conseguindo.

$\mathrm{Na}$ prática, o inserir-se profissionalmente na sociedade torna-se um ato burocrático, onde o importante é o êxito oficial, o saber reconhecido institucionalmente, numa sociedade em que o diploma substitui a certidão de nascimento. O sistema de ensino jurídico passa a funcionar, então, apenas como pré-requisito para a conquista de situações sociais mais valorizadas, na medida em que confere status.

Mesmo este status, porém, varia de estudante para estudante. Para os que vêm das classes mais abastadas, certamente o permanecer na Faculdade não representa dificuldades de ordem financeira. Assim, o status conferido pelo diploma de bacharel é aí apenas a confirmação de uma situação já existente. Entretanto, na medida em que descemos na escala social, esta permanência significa esforço e o status conferido passa a ter mais peso. Os currículos, o estilo de ensino, o conteúdo dos programas, contudo, são feitos para os primeiros e não para os segundos que, vendo no diploma uma alternativa de ascenção social, acabam por suportar um ensino que não 
toma em conta as suas aspirações. Ele sai da Faculdade e ou não encontra emprego, ou não consegue enfrentar um mercado altamente concorrente ou desiste e volta para o seu lugar de origem. Mais uma vez, o aumento meramente quantitativo de bacharéis tende a diminuir a importância do ensino ou, então, a aumentar o tempo de formação profissional em que o diploma já não é mais suficiente: é preciso, também, pós-graduação. Só que, neste caso, não estamos transformando, mas apenas reforçando o status quo.

Meus amigos, por favor, não me vejam como um pessimista. Muito menos como um cético. Meu propósito, ao levantar levemente a cortina que cobre a realidade educacional jurídica entre nós, não foi o de declarar o meu próprio desfalecimento diante de uma tarefa que parece incomensurável e sem horizontes. Ao contrário, foi o de estabelecer o compromisso de educador que não quer dobrar diante de dificuldades e, muito menos, deseja encobrir a realidade para gozar os benefícios da pseudo-inconsciência.

A educação é como a conformação lenta do mármore bruto. Exige tanto paixão como perspectiva. Somente quem tem a vocação do ensino terá a certeza de não desmoronar quando a realidade, do seu ponto de vista, for demasiado mesquinha ou demasiado exigente para o que ele quer lhe oferecer. Para quem não pode enfrentar como homem o destino de sua época, devemos reconhecer: que ele se recolha no seu silêncio, simples e quietamente. Mas se ele puder fazê-lo, exija-se dele o compromisso da sua vocação. E é para este compromisso que estou aqui.

Obrigado. 